\title{
Prontuário de Redação Oficial
}

\author{
Heloísa de Britto e Souza
}

Todo homem, orador, escritor ou poeta, todo homem que usa da palavia, não como de um meio de comunicação de suas idéias, mas como de um instrumento de trabalho, deve estudar e conhecer a fundo a fôrça e os recursos dêsse elemento de sua atividade.

JosÉ de Alencar

$$
(*)-(1)
$$

Clivro do Professor João Luiz NeY, «Prontuátio de Redação Oficial», já se encontra na quarta edição. Lançada pelo Departamento Administrativo do Pessoal Civil, como de resto, tôdas as demais, data a primeira edição de 1955 . Contém um prefácio, onde êle se refere ao exíguo prazo de 20 dias, que the impuseram, para execução dessa obra. Cumpriu-o, entretanto, com a rapidez solicitada, apesar do enorme volume de material para arrolar $e$ que necessitava de acurado estudo para sua conveniente aplicação.

A palavra Prontuário, é, por definição etimológica, um manual de indicações úteis; (2) é também, assim, que os servidores públicos deverão considerar êste livro, do qual poderão se utilizar, como de verdadeiro vade mecum.

O Prontuário de Redação Oficial, a que seu autor dedicou meticuloso cuidado na elaboração, torna-se precioso guia para quantos trabalhem em setores administrativos do funcionalismo público.

(*) As citações de obras consultadas se encontram no final do trabalho. 
Ao ensejo do presente comentário, vem-nos, à lembrança, o artigo de Daniel Camarinha da Silva, na Revista do Serviço Público, (3) em que o autor pergunta: «Há uma literatura administrativa?» Tal indagação foi feita, visando apontar a utilidade ou mesmo a necessidade do levantamento da farta $e$ esparsa matéria redatorial burocrática, através da qual pudéssemos verificar ter havido, sempre, uma redação administrativa, que buscava estilo próprio, atendendo, ou não, a requintes literários.

No livro ora em estudo, busca o autor - professor de linguagem - fugir do âmbito das controvérsias e o torna bastante didático. Ensina, corrige, esclarece, dirime dúvidas já ancestrais, entre nós e até enraizadas no campo da redação oficial. Com natural desembaraço, aplica teorias pedagógicas indispensáveis ao conhecimento de um idioma e, bem assim, aos temas que lhe são correlatos.

E por ser, também, funcionário público, é conhecedor do assunto, o que lhe facilitou a tarefa de racionalizar verdadeira caudal de documentos administrativos com que teve de lidar, para elaboração de seu trabalho. Estabeleceu, pela primeira vez, a técnica que regerá a contextura normativa dos atos burocráticos.

A $1^{\text {a }}$ edição dessa obra - declarannos êle, no prefácí preparara em atendimento à solicitação do Diretor da Escola de Serviço Público, então Cursos de Administração do DASP, para coligir tôda documentação avulsa, que permitisse facilitar estudos de redação oficial. Desta forma, viu-se o Professor João Luiz Ney, a braços com incomensurável matéria burocrática, à qual resolveu dar forma e côr; estabeleceu a definição correta para cada espécie de documento existente e anexou, ainda, modêlo próprio, acrescido de exemplos obtidos em fontes oficiais.

Apresenta a obra um questionário para a aferição da capacidade lingüistica individual, bem como da aptidão para escrever. São formuladas, então, breves perguntas, muito concisas e profundas em tôrno da faculdade de redigir de cada pessoa. Constitui êsse adendo uma tradução feita pelo próprio autor, extraída de original em inglês, publicado em Washington, em 1950, sob a epígrafe, Teste sua Redação.

O livro possui, ainda, uma parte destinada à Gramática e Estilo. Pretende ensinar ao servidor o preparo da linguagem e o processo redatorial, apresentando as regras gramaticais que visem à melhoria do estilo da redação administrativa. Este deve ser, primordialmente: sucinto, claro e objetivo - é o que nos diz o referido capítulo. E acrescenta não haver disposições gerais coercitivas para regularem o assunto. 
São vistos, também, nesse capítulo, os solecismos, as cacografias, as deformações surgidas em qualquer texto, muitas vêzes, displicentemente elaborado, inclusive outros descuidos e erros gramaticais freqüentes no vernáculo popular, apontados, aí, com muita oportunidade.

Teria o professor transformado seu livro num mero dicionário de têrmos especializados, se o tivesse limitado, apenas, a um rol de definições. A obra é, entretanto, bem mais completa, pois, contém meticulosos estudos redatoriais e filológicos, indispensáveis em levantamentos dessa natureza. Nela são fornecidas teorias de ensino vernacular e sintático, às quais foram acrescentadas citações de autores célebres.

E o autor vai mais longe, quando relaciona galicismos já implantados em nossa redação oficial. Objetiva tal destaque evitar o abuso dêsse gênero de expressões, na terminologia administrativa e preconiza um estilo claro, defensor da pureza do idioma. Esclarece, no entanto, não se tratar de xenofobia, porém de um zêlo que, sem ser extremado, tende a resguardar o patrimônio semântico, contra a exagerada intromissão de palavras estrangeiras, que acabam por empobrecer e desfigurar o vocábulário de um país, despindo-o de sua índole natural. Sabemos que isto faz qualquer lingua perder sua autenticidade, ao curso de algum tempo.

Estabeleça-se um confronto entre o autor desta obra e outro, também funcionário e também escritor, que foi Machado de Assis, pois, vale contar o que de parecido ocorreu, quando êste último foi incumbido de elaborar um levantamento a respeito de terras devolutas no Brasil, em 1885 . Usou, então, tôda a matéria por êle coligida até 1879 , quando integrara uma comissão a isso destinada, prosseguindo, apenas, a parte de pesquisas e coleta de elementos relacionados com aquela legislação, que datava de 18 de setembro de 1850. Havia sido a lei inicial, regulamentada, sòmente em 1854 e a seguir, acumuláramos farta bagagem de leis e decretos em tôrno do assunto.

Foi uma tarefa exaustiva, a de Machado de Assis, que, além disso, redigiu todo o trabalho resultante de suas compilações. Lutou, portanto, com imensa variedade de documentos a reunir, para que pudesse levar a bom têrmo a missão que rece. bera, de vez que, desta feita, se reportou ao ano de 1831 .

Publicou-o a Imprensa Nacional, sob o título - Tertas e o subtítulo Compilação para Estudo - MACHAdo DE Assis 1886; por seu intermédio, preparou-se um projeto que foi submetido ao Conselho de Estado do Império. O referido Conselho, após ligeiras alterações decorrentes de debates, remeteu-o à Assembléia Geral do Império, que, mais tarde, o transformou em decreto, aproveitando, assim, as conclusões a que chegara quem 
estudou tão farta legislação. (4) Paralelamente a Machado de Assis, o Professor João Luiz Ney se destaca, por não se ter restringido a fazer de seu Prontuário, elementar compilação. Valorizou-o ao fazer mais do que isso, apesar do precárío prazo de vinte dias, que lhe fôra concedido para realizar obra de real proveito e utilidade.

Na parte concernente à Antologia, cada título foi particularmente definido, ressaltando o autor, em pequenas introduções, que o aprimoramento do estilo redatorial se adquire por forç̧a de exercícios sistemáticos de linguagem e intenso conhecimento das obras mestras da lingua. Esclarece, mais, que, para se conseguir tal aprimoramento, é necessário persistente aplicação dos ensinamentos do idioma pátrio. Acrescenta êle, que, no caso de redação oficial, é preciso estar a par do entrosamento que há entre os órgãos da Administração Pública e da forma de tratamento adequado para as respectivas autoridades.

Assim sendo, passa a relacionar e a exemplificar os documentos indicadores dos Atos de Instrução e Movimentação dos Papéis usuais numa repartição pública, definindoros.

A amostragem dêsses atos administrativos se deve ao emprêgo generalizado de ambos, no serviço público brasileiro, sendo, por isso, muito justamente trazidos para modelos.

São tão importantes coletâneas dêsse gênero, que, hoje em dia, outros países já as estão organizando. É prova de tal afirmação o que há tempos atrás apresentou a revista argentina do I.S.A.P. - Instituto Superior de Administración Pública, de Buenos Aires, em editorial, sob o título Necesidad de un Glosario Administrativo. Ai se faz referência aos vocábulos ou expressões de uso específico e quase exclusivo da Administração Pública, que, independentemente de seu significado gramatical, recebem outro de cunho bastante burocrático. É como se existisse um léxico especial para o serviço público.

O comentário da revista em foco identifica-se com a idéia expressa por Daniel Camarinha da Silva, quando faz referência à presença da locução literatura administrativa, pois, o citado editorial exprime essa mesma hipótese. E vai mais adiante, na similitude de propósitos, ao sugerir que as palavras de linguas estrangeiras sejam excluídas de semelhante arrolamento, a fim de que o vocabulário usado possa ser escolhido dentro de estritas características locais.

Realizará o mencionado Instituto essa tarefa, servindo-se, para tanto, de um sistema de fichas individuais para cada palavra corriqueira naquele país, contendo, outrossim, o significado exato de cada uma e a doutrina que fundamenta seu particular emprêgo na redação de assuntos administrativos. 
Esclarece aquela revista que poderá colaborar nesse trabalho quem estiver relacionado com a Administração Pública Argentina e sua publicação far-se-á, paulatinamente. (5).

Compreenderse que a tarefa que êles estão fazendo, é, no todo, parecida com a que já concluiu, em 1955, o autor do Prontuário de Redação Oficial elaborado no Brasil.

Prossegue o livro, ora apreciado, com exposição de Documentos Oficiais, parte esta também acompanhada de explicações prévias dos respectivos assuntos, incluindo definições isoladas.

Vêm, então, analisados e definidos: a Ata, a Portaria, os Autos de Infração, a Carta e a Carta-Memorial, o Contrato, o Decreto, a Ementa, a Exposição de Motivos, o Memorando ou Comunicação, a Mensagem, o Requerimento, a Resolução, o Telegrama, além de outros já referidos no início dêste trabalho. Cuidadosamente selecionados os exemplos típicos dêsses documentos, alguns apresentam exemplos que são testemunhos de fatos marcantes, ocorridos em nosso passado e que provocaram papéis administrativos do caráter daqueles, ora em estudo.

Verificamos, então, que foi reunido nesse livro tudo o que de essencial precisará achar quem lida nesse mister.

Prossegue o compêndio com um Dicionário de Documentos Oficiais, em que os vocábulos, mais aplicados no linguajar burocrático, encontram adequada definição.

Segue-se outro arrolamento e êste, agora, de Têtmos e Expressões mais Freqüentes nos Documentos Oficiais. Nêle são mostradas, inclusive, locuções latinas já vulgarizadas nesse setor de atividades, além de explicações sôbre o emprêgo delas.

Já quase ao final, vêm sugeridos alguns Exercícios de Redação oficial, fornecendo o autor os dados para sua execução, mais a quantidade de linhas a serem gastas e assunto para os mesmos.

Constam, ainda, dos exemplares da $4^{a}$ edição - DASP Serviço de Documentação - 1965 - algumas Abreviaturas dos Estados e Territórios do Brasil, abreviaturas essas usadas em todo o país, na correspondência oficial e, especificamente, na telegráfica.

Antes do Indice Geral que lhe dá fecho, há uma relação das Principais Abreviaturas e Siglas Usadas nos Documentos Oficiais e Consignadas no Pequeno Vocabulátio Ottográfico da Lingua Portuguêsa, dispostas por ordem alfabética.

Desta nossa publicação, cujo comentário, embora débil, prevalece a observação de se tratar de matéria de real valor para o funcionalismo público em geral. 


\section{CITAÇÕES FEITAS NO CORPO DO TRABALHO}

1) José DE Alencar: Antologia Nacional - Fausto Batreto e Carlos de Laet, adaptação pelo Prof. M. Daltro Santos. $37^{4}$ edição, 1960.

2) Pequeno Dicionário Brasileiro da Lingua Portuguêsa - organizado por Hildebrando de Lima e Gustavo Barroso e revisto na parte geral por Manuel Bandeira e José Baptista da Luz - 9* edição, pág. 995. Revisto na parte de brasileirismo, por Aurélio Buarque de Hollanda Ferreira.

3) Revista do Serviço Público - Volume 67 - $\mathrm{N}^{\circ} 2$ - Maio de 1955 - pág. 209 - Daniel Camarinha da Silva, artigo intitulado «Há uma literatura administrativa?» - Editor: DASP - Serviço de Documentação.

4) MACHAdo DE Assis, Funcionário Público, por Raimundo Magalhães Jr. - Coleção Mauá (M.V.O.P.) - 1958.

5) Revista de Administración Pública - I.S.A.P. - Secretaria de Hacienda de la República Argentina - No $17-1965$ - Buenos Aires, Argentina. 